\title{
Association of injury related hospital admissions with commuting by bicycle in the UK: prospective population based study
}

\author{
Claire Welsh, ${ }^{1}$ Carlos A Celis-Morales, ${ }^{1,2,3}$ Frederick Ho, ${ }^{1}$ Donald M Lyall, ${ }^{3}$ Daniel Mackay, ${ }^{4}$ \\ Lyn Ferguson, ${ }^{1}$ Naveed Sattar, ${ }^{1}$ Stuart R Gray, ${ }^{1}$ Jason M R Gill, ${ }^{1}$ Jill P Pell, ${ }^{3}$ Paul Welsh ${ }^{1}$
}

${ }^{1}$ Institute of Cardiovascular and Medical Sciences, University of Glasgow, BHF Glasgow Cardiovascular Research Centre, Glasgow, G12 8TA, UK

${ }^{2}$ Centre for Exercise Physiology Research (CIFE), Universidad Mayor, Santiago, San Pío, Chile

${ }^{3}$ Institute of Health and Wellbeing, University of Glasgow, Glasgow, UK

${ }^{4}$ School of Medicine, Dentistry and Nursing, University of Glasgow, UK

Correspondence to:P Welsh paul.welsh@glasgow.ac.uk (or@UofGICAMS on Twitter ORCID 0000-0002-7970-3643) Additional material is published online only. To view please visit the journal online.

Cite this as: $B M J$ 2020;368:m336 http://dx.doi.org/10.1136/bmj.m336

Accepted: 16 January 2020

\section{ABSTRACT}

OBJECTIVE

To determine whether bicycle commuting is

associated with risk of injury.

DESIGN

Prospective population based study.

SETTING

UK Biobank.

PARTICIPANTS

230390 commuters (52.1\% women; mean age 52.4 years) recruited from 22 sites across the UK compared by mode of transport used (walking, cycling, mixed mode versus non-active (car or public transport)) to commute to and from work on a typical day.

MAIN OUTCOME MEASURE

First incident admission to hospital for injury.

RESULTS

5704 (2.5\%) participants reported cycling as their main form of commuter transport. Median follow-up was 8.9 years (interquartile range 8.29.5 years), and overall 10241 (4.4\%) participants experienced an injury. Injuries occurred in 397 (7.0\%) of the commuters who cycled and 7698 (4.3\%) of the commuters who used a non-active mode of transport. After adjustment for major confounding sociodemographic, health, and lifestyle factors, cycling to work was associated with a higher risk of injury compared with commuting by a non-active mode (hazard ratio $1.45,95 \%$ confidence interval 1.30 to 1.61). Similar trends were observed for commuters who used mixed mode cycling. Walking to

\section{WHAT IS ALREADY KNOWN ON THIS TOPIC}

Cycling commuting has been associated with a lower risk of morbidity and mortality

A key barrier to the uptake of commuter cycling among the public includes perceived and objective traffic danger

Individual level evidence on cycling and injuries is, however, limited

\section{WHAT THIS STUDY ADDS}

Our study suggests that commuting by cycling is associated with a $45 \%$ higher risk of admission to hospital for an injury and 3.4-fold higher risk of a transport related injury

Commuting longer distances by cycling is associated with a higher risk of injury than shorter distances, whereas distance was not associated with injury rate in non-active commuters

If 1000 participants changed their mode of commuting to include cycling for 10 years, this would translate into an estimated additional 26 hospital admissions for a first injury (of which three would require a hospital stay of a week or longer), 15 fewer first cancer diagnoses, four fewer cardiovascular disease events, and three fewer deaths work was not associated with a higher risk of injury. Longer cycling distances during commuting were associated with a higher risk of injury, but commute distance was not associated with injury in non-active commuters. Cycle commuting was also associated with a higher number of injuries when the external cause was a transport related incident (incident rate ratio $3.42,95 \%$ confidence interval 3.00 to 3.90 ). Commuters who cycled to work had a lower risk of cardiovascular disease, cancer, and death than those who did not. If the associations are causal, an estimated 1000 participants changing their mode of commuting to include cycling for 10 years would result in 26 additional admissions to hospital for a first injury (of which three would require a hospital stay of a week or longer), 15 fewer first cancer diagnoses, four fewer cardiovascular disease events, and three fewer deaths.

\section{CONCLUSION}

Compared with non-active commuting to work, commuting by cycling was associated with a higher risk of hospital admission for a first injury and higher risk of transport related incidents specifically. These risks should be viewed in context of the health benefits of active commuting and underscore the need for a safer infrastructure for cycling in the UK.

\section{Introduction}

A large and consistent evidence base from prospective cohort studies suggests that regular physical activity is associated with many positive health outcomes, including a lower risk of mortality and lower incidence of cardiovascular disease, stroke, hypertension, type 2 diabetes, and some cancers (principally breast and colon). ${ }^{1-4}$ Despite this, 20 million adults in the UK are failing to meet government recommendations for physical activity ( $\geq 150$ minutes of moderate physical activity weekly), increasing their risk of heart disease and costing the UK health service as much as $£ 1.2 \mathrm{bn}$ (\$1.6bn; €1.4bn) each year. ${ }^{5}$ One way in which people can incorporate physical activity into their day is to use an active mode of commuting, ${ }^{6-9}$ and recent evidence has shown that active modes of commuting, including cycling, result in improved fitness and lower adiposity ${ }^{10}$ and are associated with a lower risk of cardiovascular disease, cancer, type 2 diabetes, and all cause mortality. ${ }^{11-15}$

Despite the apparent benefits of cycling, the number of people commuting by bicycle in the UK and many other countries is low. ${ }^{16}$ The British Social Attitudes survey of adults ( $\geq 18$ years) suggests that only $4 \%$ of people cycle to work once a week despite 39\% owning a bicycle, and $64 \%$ of respondents agreed or strongly 
agreed that cycling on roads is too dangerous. ${ }^{17}$ Indeed, a systematic review, including 21 observational studies from five countries that investigated the association between cycling infrastructure and levels of cycling reported on key barriers to cycling at environmental level, which included perceived and objective traffic related dangers. ${ }^{18}$ Evidence on cycling and injuries from the UK is limited and suggests that for cyclists the risks increase with age, whereas for young men, cycling has lower fatality rates per unit time travelling than driving. ${ }^{19}$ It is important to empirically validate the perception of the increased risk of injury among cyclists and what benefits might be expected from successful infrastructure interventions to promote safety. This information is pertinent to policy makers when devising strategies to improve public health through active commuting, by highlighting potential risks and to help realise greater benefits of increased active commuting in the UK general population. ${ }^{20}$

We used the UK Biobank cohort to investigate the association between bicycle commuting and risk of injury compared with other forms of commuting transport.

\section{Methods \\ UK Biobank}

The UK Biobank cohort includes 502536 participants (aged 37-73 years, 54.4\% women) recruited between 2006 and 2010 from across the UK. Baseline assessments conducted at 22 assessment centres included a touch screen questionnaire covering an extensive range of health and lifestyle factors, a

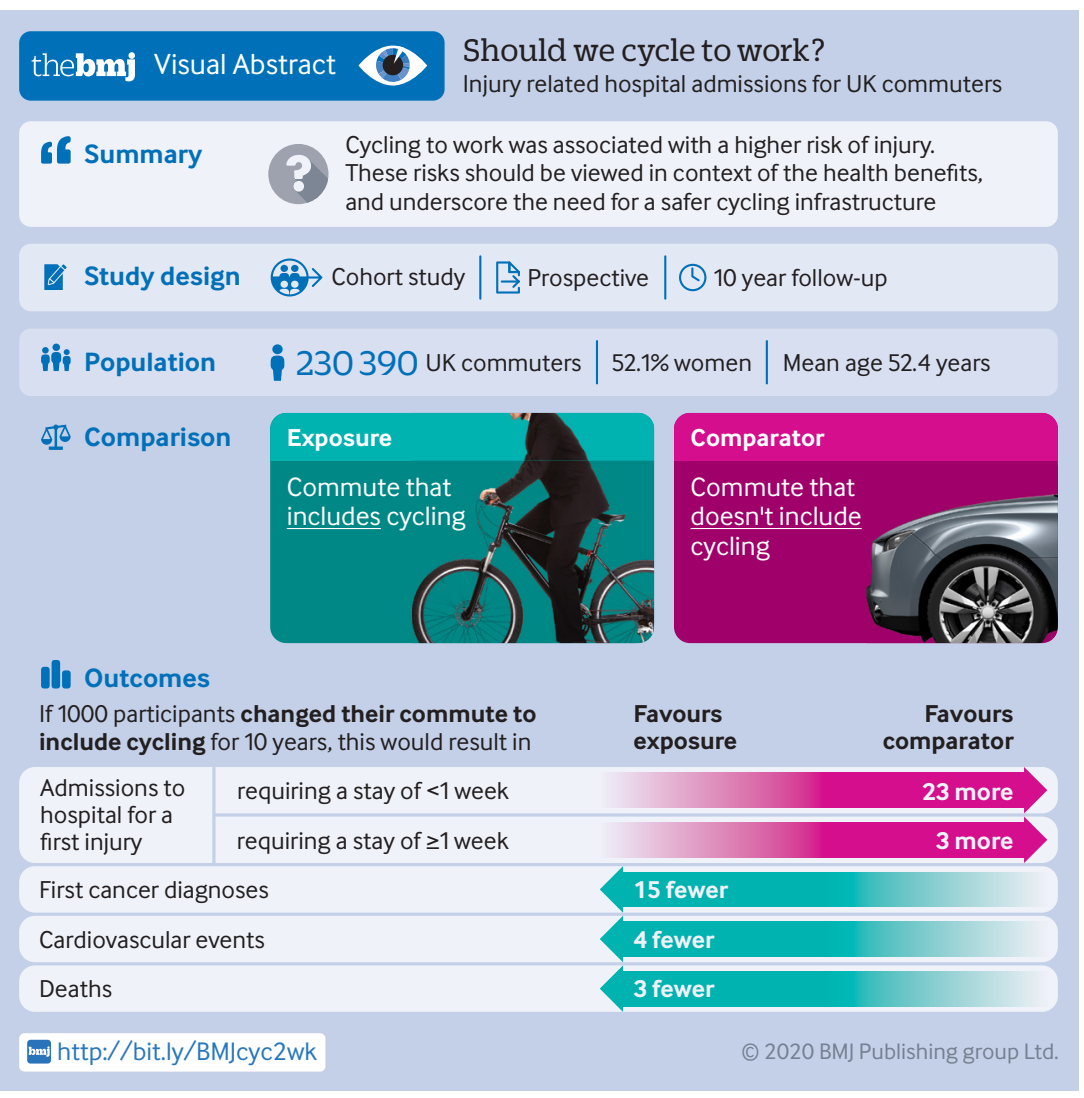

computer assisted verbal interview, a wide range of physical tests, and collection of several biological samples. This information was then linked, with permission, to death records. We obtained the date and cause of death from death certificates held by the National Health Service Information Centre for participants from England and Wales and the NHS Central Register Scotland for participants from Scotland. Baseline data were also linked to hospital episode statistics data. Further details on procedures and sample analyses can be found in the UK Biobank online showcase and protocol (www.ukbiobank.ac.uk).

\section{Measurement of exposures}

We excluded participants who had not provided information on their commute, did not work $(n=238263)$, reported highly unrepresentative commuting distances ( $>200$ miles per journey), reported commuting more than 12 times a week $(n=18031)$, or had missing data for covariates ( $n=15312$ ). Participants who reported commuting to work less than once a week were assigned a value of 0.5 for frequency of commuting, those who reported a commute distance of less than 1 mile $(1.6 \mathrm{~km})$ were assigned a value of 0.5 miles, and those who reported a rounded zero miles between home and workplace were assigned a value of 0.3 miles. At baseline we used the mode of transportation from an electronic questionnaire with response to the question: "In a typical day, what types of transport do you use to get to and from work?" Responders could select one or more of: car/motor vehicle, walk, public transport, and cycle. We derived five commuting categories: non-active (car/ motor vehicle or public transport), walking, cycling, mixed mode walking (non-active plus walking), and mixed mode cycling (cycling plus other modes). As such, the definition of commuters exclusively cycling to work is stricter in this paper than in previous work. ${ }^{11}$ We also used a binary commuting variable in which people included or did not include cycling at all in their commute. The weekly commuting distance was derived from the single commuting distance multiplied by 2 to obtain a round trip distance and by the weekly number of round trips reported by the participant.

To account for each participant's leisure time physical activity levels, we constructed a composite variable combining two exercise related variables (number of days doing 10 minutes or more of moderate physical activity each week, and similarly for vigorous activity) by first categorising both moderate and vigorous physical activity variables into three categories ( 0 days/week=0,1-3 days/week=1, and $>3$ days/week $=2$ ) and then summing the resultant categories. Five levels of physical activity scores (score 0-4) were thereby derived. For presentation we summarised these levels as inactive (score $=0$ ), moderate (score=1-3), or active (score $=4$ ), but the five level score was used in adjustment models. Location of home area was used as a binary variable representing urban/town area, or other areas that were "rural" (village/hamlet/rural) according to postcode and the 
2001 census national statistics. Body mass index (BMI) was categorised into underweight $(<18.5 \mathrm{~kg} /$ $\mathrm{m}^{2}$ ), normal weight (18.5-24.9), overweight (2529.9), and obese ( $\geq 30$ ). Smoking status and alcohol consumption were self-reported. Presence of baseline cardiovascular disease was defined as self-reported "heart attack", angina, or stroke. Baseline cancer, depression, and longstanding illness were also selfreported. The presence of baseline diabetes was based on self-reported diabetes diagnosis or use of diabetes drugs. Hypertension was self-reported or identified from a baseline systolic blood pressure of $>140 \mathrm{~mm}$ $\mathrm{Hg}$ or diastolic blood pressure $>90 \mathrm{~mm} \mathrm{Hg}$.

\section{Measurement of outcomes}

As changes in mode of commuting might occur after an index injury, we used time to first event analysis in the primary model. The primary outcome of interest was any injury (international classification of diseases, 10th revision (ICD-10) codes S00-S99, T00-T14, V00-V99) that resulted in a first hospital admission in hospital episode statistics, or death with injury as the primary cause. Hospital admission data included diagnoses from emergency departments as well as from inpatient records. Further sensitivity analyses restricted the outcome to injuries of the arms or legs (appendicular, ICD-10 codes S40-S99), trunk (S20-S39), or head or neck (S00-S19), and fractures (S02, S12, S22, S32, S42, S52, S62, S72, S82, S92, S07, T02, T10, or T12). Follow-up for participants began at their baseline assessment and ended at their first recorded injury, the end of follow-up at the assessment centre (30 November 2016 in Scotland and 31 January 2018 in England or Wales), or death, whichever came first. In all the groups, a proportion of the injuries will not be specifically due to mode of commuting, but the model assumes that excess risk of injury occurs as a result of differences in commuting between groups.

In a secondary analysis we investigated injuries that were specifically coded as transport related incidents. As such, the outcome of interest was number of transport incidents per person in the external causes of hospital episode statistics (ICD-10 codes V00-V99) during follow-up. We also specifically investigated cycle related transport incidents in the external causes of hospital episode statistics (ICD-10 codes V10-V19) as an internal validation; those who reported commuting by cycling should have a greater number of cycle related transport incidents.

To place the injury data in context, we conducted a further analysis to investigate the association of mode of commuting with morbidity and mortality, updating previous work ${ }^{11}$ (the models reported here differ for defined commuting types and outcomes). Incident cardiovascular disease was defined as admission to hospital for myocardial infarction or stroke (ICD-10 codes I21, I22, I60-64) or death from cardiovascular disease (I20-I25; I60-I64) (primary cause), and incident cancer was defined as admission to hospital for cancer or death from cancer (primary cause) (codes C00-C99, D00-D48) among those who reported no previous cancer.

\section{Statistical analyses}

The distribution of baseline characteristics was investigated across commuting modes (non-active, walking, cycling, mixed mode walking, or mixed mode cycling), displayed as means (standard deviations) if normal, medians (interquartile ranges) if skewed, and numbers (percentages) if categorical. Tests of differences across modes were conducted by analysis of variance, Kruskal-Wallis, and $\chi^{2}$, respectively.

For each group we calculated the incidence rate of first hospital episodes attributed to injury for each 10000 miles commuted by dividing the mean number of injury related hospital admissions weekly (assuming six weeks of annual leave in a year) by the number of miles travelled each week (commute distance multiplied by 2 and by the number of days the participant commuted each week). The incidence rate of first injury related hospital admission per 1000 person years was calculated using a simple counting method. To calculate the number of hours participants spent commuting, we used external data to model walking at 3.4 miles per hour (mph, $5.5 \mathrm{~km} / \mathrm{h}$ ), cycling at $8.3 \mathrm{mph}(13.4 \mathrm{~km} / \mathrm{h})$, and driving at $27.6 \mathrm{mph}(44.4$ $\mathrm{km} / \mathrm{h}){ }^{19}$

We then investigated the association of injury with commuting mode using Cox proportional hazard models. Competing risks models were also investigated using non-cardiovascular disease related death as the competing risk, but as the hazard ratios were not meaningfully impacted we used the simpler model. Cox models were adjusted first for age and sex, then additionally for ethnicity, Townsend deprivation index score, comorbidities (longstanding selfreported illness, diabetes, hypertension, baseline cardiovascular disease, previous cancer, and depression), BMI, smoking (never, former, current), alcohol drinker status (never, former, current), and five levels of physical activity. The proportional hazards assumption was checked by visual inspection of Schöenfeld residuals. The association of the commuting groups with the secondary outcomes of specific injury subtypes was modelled using a time to first event model for each injury subtype separately. We used the same models for outcomes of cardiovascular disease, cancer, and all cause mortality. The primary analyses were also stratified in six additional ways: by category of distance travelled (one way) on a typical commute, sex, residential area (urban/town versus rural), binary physical activity (moderate or low versus high), binary assessment date (before versus after 1 January 2010), and length of hospital stay. Assessment dates that occur after January 2010 are intended to act as a proxy for provision of potentially improved cycling infrastructure in some areas after this date, ${ }^{21-23}$ which might reduce cycling associated injuries. Length of hospital stay is intended to act as a proxy for injury severity.

For the secondary outcome of transport incidents, we reported the mean number of events recorded for each participant over the follow-up time in each commuting group, and expressed these as mean events per 100 
persons. A negative binomial model with constant dispersion, robust standard errors, and identical adjustment to the Cox models was utilised to obtain the incidence rate ratio of transport incidents by mode of commuting. ${ }^{24}$ We also applied the model to cycling related transport incidents. To calculate the adjusted absolute rate difference between cyclists and noncyclists for different outcomes, we firstly calculated the incidence rate of non-cyclists (base rate). The injury rate of cyclists was then estimated by applying incidence rate ratios from a negative binomial model (offsetting for logged follow-up time) onto the base rate. All analyses were conducted in STATA version 15.1.

\section{Patient and public involvement}

The UK Biobank resource included extensive public consultation in its design. No participants were involved in setting this research question or the outcome measures, nor were they involved in developing plans for design or implementation of the study. No participants were asked to advise on interpretation or writing up of results.

\section{Results}

Baseline characteristics

Of the 230390 participants (52.1\% women, mean age 52.4 years) who self-reported their commute type, 5704 (2.5\%) reported exclusively cycling. Compared with non-active commuters ( $\mathrm{n}=178976$, $77.5 \%$ ), cycle commuters were slightly younger, had a lower BMI, were more likely to be white men, and less likely to be a current smoker or have a history of cardiovascular disease, diabetes, cancer, or longstanding illness (table 1). They were also more likely to be physically active in leisure time (table 1). Mixed mode commuter cyclists $(n=13380,5.8 \%)$ also had a broadly healthier profile than non-active commuters.

\section{Incidence of injury}

Across all participants, the median follow-up time was 8.9 years (interquartile range 8.2-9.5 years), and 10241 (4.4\%) participants had at least one hospital admission for an injury or died with injury listed as the primary cause $(\mathrm{n}=29$ died). Those who were injured were generally older and more likely to be white men and to be a current smoker and have a history of cardiovascular disease, diabetes, cancer, or longstanding illness (table 2). A trend was also observed whereby those injured were slightly more likely to be physically active, although BMI was not associated with injury (table 2).

Injuries were experienced by $397(7.0 \%)$ of the participants who reported commuting by cycling

\begin{tabular}{|c|c|c|c|c|c|}
\hline Characteristics & $\begin{array}{l}\text { Non-active } \\
(\mathrm{n}=178976)\end{array}$ & $\begin{array}{l}\text { Walk } \\
(n=12352)\end{array}$ & $\begin{array}{l}\text { Cycle } \\
(n=5704)\end{array}$ & $\begin{array}{l}\text { Mixed mode: walk } \\
(\mathrm{n}=20518)\end{array}$ & $\begin{array}{l}\text { Mixed-mode: cycle } \\
(n=13380)\end{array}$ \\
\hline Mean (SD) age (years) & $52.6(7.0)$ & $52.9(7.0)$ & $51.4(7.0)$ & $52.3(6.8)$ & $50.3(6.7)$ \\
\hline Women & $92393(51.6)$ & $8413(68.1)$ & $1961(34.4)$ & 12709 (61.9) & $4754(35.5)$ \\
\hline Men & $86583(48.4)$ & 3939 (31.9) & $3743(65.6)$ & 7809 (38.1) & $8626(64.5)$ \\
\hline \multicolumn{6}{|l|}{ Ethnicity: } \\
\hline White & $169649(94.8)$ & 11733 (95.0) & 5508 (96.6) & $19436(94.7)$ & 12977 (97.0) \\
\hline Black & $2862(1.6)$ & $160(1.3)$ & $44(0.8)$ & $334(1.6)$ & $113(0.8)$ \\
\hline South Asian & $2781(1.6)$ & $158(1.3)$ & $21(0.4)$ & $276(1.3)$ & $67(0.5)$ \\
\hline Other & $3684(2.1)$ & $301(2.4)$ & $131(2.3)$ & $472(2.3)$ & $223(1.7)$ \\
\hline \multicolumn{6}{|l|}{ Smoking status: } \\
\hline Never & $103234(57.7)$ & $7207(58.3)$ & $3285(57.6)$ & $12474(60.8)$ & $7875(58.9)$ \\
\hline Former & $56620(31.6)$ & $3773(30.5)$ & $1878(32.9)$ & $6281(30.6)$ & $4388(32.8)$ \\
\hline Current & $19122(10.7)$ & $1372(11.1)$ & $541(9.5)$ & $1763(8.6)$ & $1117(8.3)$ \\
\hline Baseline cardiovascular disease & $5420(3.0)$ & $333(2.7)$ & $99(1.7)$ & $446(2.2)$ & $228(1.7)$ \\
\hline $\begin{array}{l}\text { Median (interquartile range) Townsend } \\
\text { deprivation index }\end{array}$ & $-2.39(-3.77,-0.10)$ & $-0.47(-2.68,2.31)$ & $-0.91(-2.91,1.80)$ & $-1.51(-3.33,1.15)$ & $-1.88(-3.54,0.62)$ \\
\hline Longstanding illness & $44173(24.7)$ & $2832(22.9)$ & $1081(19.0)$ & $5034(24.5)$ & $2653(19.8)$ \\
\hline \multicolumn{6}{|l|}{ Physical activity: } \\
\hline Sedentary & $23013(12.9)$ & $1228(9.9)$ & $4(0.1)$ & $2500(12.2)$ & $152(1.1)$ \\
\hline Moderately active & $128897(72.0)$ & $8893(72.0)$ & $2192(38.4)$ & $15488(75.5)$ & $8550(63.9)$ \\
\hline Very active & $27066(15.1)$ & $2231(18.1)$ & $3508(61.5)$ & $2530(12.3)$ & $4678(35.0)$ \\
\hline Previous cancer & $10073(5.6)$ & $742(6.0)$ & $247(4.3)$ & $1120(5.5)$ & $606(4.5)$ \\
\hline Diabetes & $6500(3.6)$ & $349(2.8)$ & $98(1.7)$ & $625(3.0)$ & $229(1.7)$ \\
\hline Hypertension & $86610(48.4)$ & $5682(46.0)$ & 2191 (38.4) & $9285(45.3)$ & 5237 (39.1) \\
\hline Depression & 35617 (19.9) & $2543(20.6)$ & $1289(22.6)$ & $5102(24.9)$ & $3309(24.7)$ \\
\hline \multicolumn{6}{|l|}{ Mean (SD) body mass index $\left(\mathrm{kg} / \mathrm{m}^{2}\right)$ : } \\
\hline$<18.5$ & $737(0.4)$ & $97(0.8)$ & $54(0.9)$ & $123(0.6)$ & $66(0.5)$ \\
\hline $18.5-24.9$ & $58223(32.5)$ & $5227(42.3)$ & $2941(51.6)$ & $7942(38.7)$ & $5737(42.9)$ \\
\hline $25.0-29.9$ & $76492(42.7)$ & $4789(38.8)$ & $2187(38.3)$ & $8242(40.2)$ & $5714(42.7)$ \\
\hline$\geq 30.0$ & $43524(24.3)$ & $2239(18.1)$ & $522(9.2)$ & $4211(20.5)$ & $1863(13.9)$ \\
\hline \multicolumn{6}{|l|}{ Alcohol drinker status: } \\
\hline Never & $5446(3.0)$ & $559(4.5)$ & 109 (1.9) & $664(3.2)$ & $214(1.6)$ \\
\hline Former & $4537(2.5)$ & $427(3.5)$ & $192(3.4)$ & $547(2.7)$ & $300(2.2)$ \\
\hline Current & $168993(94.4)$ & $11366(92.0)$ & $5403(94.7)$ & 19307 (94.1) & $12866(96.2)$ \\
\hline
\end{tabular}




\begin{tabular}{|c|c|c|}
\hline Characteristics & $\begin{array}{l}\text { No injury } \\
(n=220689)\end{array}$ & $\begin{array}{l}\geq 1 \text { injury } \\
(n=10241)\end{array}$ \\
\hline Mean (SD) age (years) & $52.4(7.0)$ & $53.3(7.2)$ \\
\hline \multicolumn{3}{|l|}{ Sex: } \\
\hline Women & $115103(52.2)$ & $5127(50.1)$ \\
\hline Men & $105586(47.8)$ & $5114(49.9)$ \\
\hline \multicolumn{3}{|l|}{ Ethnicity: } \\
\hline White & $209393(94.9)$ & $9910(96.8)$ \\
\hline Black & $3431(1.6)$ & $82(0.8)$ \\
\hline South Asian & $3207(1.5)$ & $96(0.9)$ \\
\hline Other & $4658(2.1)$ & $153(1.5)$ \\
\hline \multicolumn{3}{|l|}{ Smoking status: } \\
\hline Never & $128444(58.2)$ & $5631(55.0)$ \\
\hline Former & $69622(31.5)$ & $3318(32.4)$ \\
\hline Current & $22623(10.3)$ & $1292(12.6)$ \\
\hline Baseline cardiovascular disease & $6131(2.8)$ & 395 (3.9) \\
\hline Median (interquartile range) Townsend deprivation index & $-2.20(-3.68,0.26)$ & $-2.01(-3.55,0.63)$ \\
\hline Longstanding illness & $52832(23.9)$ & $2941(28.7)$ \\
\hline \multicolumn{3}{|l|}{ Physical activity: } \\
\hline Sedentary & $25808(11.7)$ & $1089(10.6)$ \\
\hline Moderately active & $157117(71.2)$ & $6903(67.4)$ \\
\hline Very active & $37764(17.1)$ & $2249(22.0)$ \\
\hline Previous cancer & $12153(5.5)$ & $635(6.2)$ \\
\hline Diabetes & $7384(3.3)$ & $417(4.1)$ \\
\hline Hypertension & $103876(47.1)$ & $5129(50.1)$ \\
\hline Depression & $45885(20.8)$ & 1975 (19.3) \\
\hline \multicolumn{3}{|l|}{ Body mass index $\left(\mathrm{kg} / \mathrm{m}^{2}\right)$ : } \\
\hline$<18.5$ & $1025(0.5)$ & $52(0.5)$ \\
\hline $18.5-24.9$ & $76493(34.7)$ & 3577 (34.9) \\
\hline $25.0-29.9$ & $93138(42.2)$ & 4286 (41.9) \\
\hline$\geq 30.0$ & $50033(22.7)$ & $2326(22.7)$ \\
\hline \multicolumn{3}{|l|}{ Alcohol drinker status: } \\
\hline Never & $6708(3.0)$ & $284(2.8)$ \\
\hline Former & $5709(2.6)$ & $294(2.9)$ \\
\hline Current & $208272(94.4)$ & $9663(94.4)$ \\
\hline
\end{tabular}

and $806(6.0 \%)$ of the participants who reported commuting by mixed mode cycling. This compared with injury in 7698 (4.3\%) non-active commuters, 541 (4.4\%) commuters who walked, and 799 (3.9\%) participants who commuted by mixed mode walking.

The incidence rates of injury per 1000 person years, show that cycling was associated with higher rates (fig 1, supplementary table s1). The cycling group experienced 8.06 events per 1000 person years versus 4.96 events per 1000 person years in non-active commuters $(\mathrm{P}<0.001)$. Injury rates were also higher in mixed mode cycling commuters compared with non-active commuters (6.99 events per 1000 person years). Those who cycled further (either exclusively or as mixed mode) had a greater risk of injury (fig 1). In contrast, there was no evidence that greater commute distance was associated with higher risk of injury in other commuter groups (fig 1).

\section{Multivariable analysis of injury}

Using age and sex adjusted hazard ratios, commuters who exclusively cycled were at $67 \%$ higher risk of first injury than non-active commuters (supplementary table s1). Mixed mode cycling commuters were at $47 \%$ higher risk. After adjusting for age, sex, and estimated hours spent commuting, the association was attenuated to a 33\% higher risk among commuters who exclusively cycled (supplementary table s2).

After extensive adjustment, the association of cycling with injury remained strong whether those who exclusively commuted by cycling (hazard ratio 1.45 , $95 \%$ confidence interval 1.30 to 1.61 ) or by mixed mode cycling $(1.39,1.29$ to 1.50$)$ were considered (fig 2, supplementary table s3) compared with non-active commuters. When those who commuted to work by cycling (exclusively or mixed mode) were compared with all other commuters, after adjustment those who incorporated cycling at all in their commute were at 1.43 -fold (95\% confidence interval 1.34-fold to 1.52fold) increased risk of injury. Given the background rate of 4.93 injuries per 1000 person years in those who did not include cycling in their commute, the absolute risk difference was 2.59 first injuries per 1000 person years among cycling commuters.

Commuting by exclusively cycling and mixed mode cycling were associated with higher risk of appendicular, trunk, head or neck, and fracture injuries specifically (table 3). Among commuters who exclusively cycled, the association was stronger for head or neck injuries and for fractures (table 3).

Commuters were more likely to walk or cycle to work if the commute distance was five miles or less; $12 \%$ of commuters reported at least partly using a bicycle if their commute was five miles or less (supplementary table s3). Evidence was found that commute by cycling over larger distances was associated with higher risk of injury even after adjustment (fig 2, supplementary table s3). Both men and women were at higher risk of injury if they commuted by cycling, although the estimate was slightly stronger in men (supplementary table s4). No strong evidence was found of an interaction between residential location (urban/rural), or physical activity with commute mode and risk of injury. There was a trend towards a stronger association of cycling with injury in those with baseline assessment after 1 January 2010 (supplementary table s4).

Exclusive commuting by cycling was strongly associated with injury related admissions to hospital of 1 day, 2-6 days, and 7 or more days, (supplementary table s5). Only $1211(11.8 \%)$ of injuries in all commuters resulted in a hospital admission for 7 or more days, and the proportion was similar in exclusive cyclists $(n=48,12.1 \%)$. Commuting by mixed mode cycling was also associated with injuries in all lengths of hospital stay (supplementary table s5).

\section{Multivariable analysis of transport incidents}

The number of hospital admissions specifically as a result of transport incidents was strongly associated with commuting mode. Exclusive and mixed mode commuting by bicycle were associated with 3.42fold (3.00-fold to 3.90-fold) and 2.62-fold (2.37fold to 2.91-fold) higher risk (table 4). As an internal validation, commute by cycling was also strongly associated with hospital admissions specifically related to cycling transport incidents (table 4). 


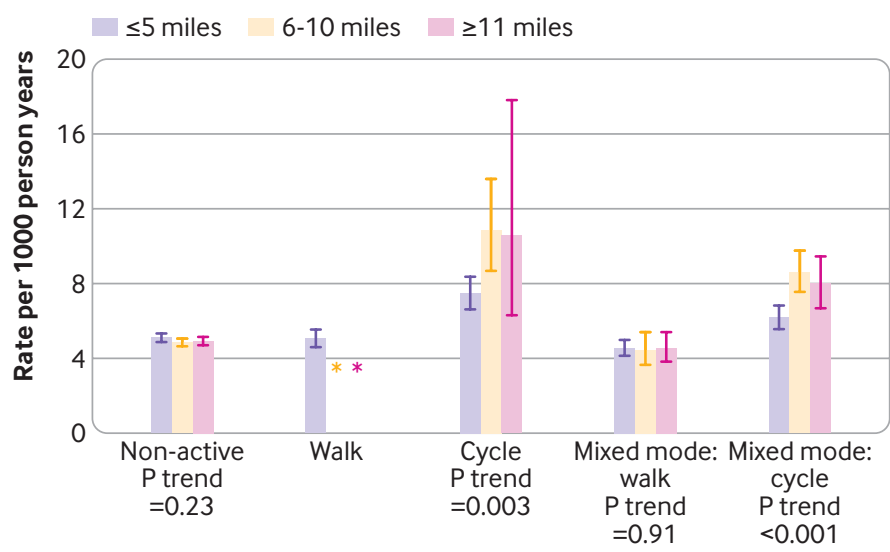

Fig 1 | Incidence rates (per 1000 person years) for first injury by commute mode and by commute distance. Data were insufficient to estimate injury rates for participants who exclusively walked more than five miles during a commute. Error bars are $95 \%$ confidence intervals. $P$ values are tests for linear trend in rates across distance categories all other commuters, after adjustment those who incorporated cycling in their commute showed a reduced risk of cardiovascular disease (hazard ratio $0.79,95 \%$ confidence interval 0.69 to 0.90 ), first cancer diagnosis $(0.89,0.84$ to 0.94$)$, and all cause mortality $(0.88,0.78$ to 1.00$)$ and the similar trends were observed in exclusive and mixed mode cyclists separately (supplementary table 6). Given the background rate of 12.96 first cancers, 1.99 cardiovascular disease events, and 2.41 deaths per 1000 person years in those who did not include cycling in their commute, cyclists have an adjusted absolute risk difference of 1.53 fewer first cancers, 0.43 fewer cardiovascular disease events, and 0.27 fewer deaths per 1000 person years.

\section{Discussion}

Our results support the reported perception ${ }^{17}$ among the general public that cycling in the UK, specifically for commuting purposes, is associated with a higher risk of injuries. Although our study also showed that those who commuted by cycling had a lower risk of cardiovascular disease and cancer than non-active commuters, such health benefits will only be achieved by those who take up cycling. The risk of injury associated with cycling commuting needs to be taken seriously and a safer infrastructure provided if we are to address cycling dangers (both real and perceived) in the UK. This could help increase the uptake of cycling commuting with resulting benefits to health and the environment.

Widespread health advice from bodies such as the World Health Organization, NHS, and National Institute for Health and Care Excellence advocate increased physical activity in the general population to improve health, ${ }^{825}$ and active commuting has been suggested as one possible solution. The present data suggest that the higher risk of injury associated with cycle commuting is real, but seems to be outweighed by the health benefits. We show that commuting by bicycle in the UK is associated with a $45 \%$ higher risk of hospital admission for a first injury, independent of confounders including physical activity levels. This equates to 26 additional first injuries for 1000 people changing modes of commuting to include cycling in their commute for 10 years. Of these additional injuries, three would require hospital stays of a week or longer. This higher risk of injury is offset by the expected benefit of 15 fewer first cancers, four fewer cardiovascular disease events, and three fewer deaths. In line with this, one previous study has suggested a benefit:risk ratio of $77: 1 .^{26}$ Secondly, we also report that cycling longer distances was associated with a higher risk of injury. Thirdly, to consider injuries when the mode of commute was more likely attributable as the external cause of injury, we specifically investigated hospital admissions for injuries when the external cause was listed as a transport incident. We estimated that people who exclusively cycled to work were at 3.4fold higher risk of injury due to a transport incident, compared with non-active commuters.

Fig 2 | Adjusted hazard ratios ( $95 \%$ confidence intervals) for injury by commuting mode, in the full cohort and stratified by one way commute distance. *Insufficient data for walking commuters. Models adjusted for age, sex, ethnicity, Townsend deprivation index score, comorbidities (longstanding illness, diabetes, hypertension, cardiovascular disease, cancer, and depression), body mass index, smoking, alcohol drinker status, and five physical activity levels 


\begin{tabular}{|c|c|c|c|}
\hline $\begin{array}{l}\text { Injury type/location by commute } \\
\text { mode }\end{array}$ & No (\%) injured & $\begin{array}{l}\text { Adjusted hazard ratio* } \\
(95 \mathrm{Cl})\end{array}$ & $P$ value \\
\hline \multicolumn{4}{|l|}{ Appendicular: } \\
\hline Non-active & $5700(3.2)$ & 1 (ref) & \\
\hline Walk & $397(3.2)$ & $0.94(0.85$ to 1.05$)$ & 0.28 \\
\hline Cycle & $267(4.7)$ & $1.37(1.21$ to 1.56$)$ & $<0.001$ \\
\hline Mixed mode: walk & $595(2.9)$ & 0.91 (0.83 to 0.99) & 0.03 \\
\hline Mixed mode: cycle & $556(4.2)$ & $1.33(1.21$ to 1.45$)$ & $<0.001$ \\
\hline \multicolumn{4}{|l|}{ Trunk: } \\
\hline Non-active & $763(0.4)$ & 1 (ref) & \\
\hline Walk & $48(0.4)$ & $0.90(0.67$ to 1.21$)$ & 0.51 \\
\hline Cycle & $46(0.8)$ & $1.53(1.12$ to 2.08$)$ & 0.007 \\
\hline Mixed mode: walk & $73(0.4)$ & $0.88(0.69$ to 1.12$)$ & 0.28 \\
\hline Mixed mode: cycle & $89(0.7)$ & $1.44(1.15$ to 1.81$)$ & 0.001 \\
\hline \multicolumn{4}{|l|}{ Head/neck: } \\
\hline Non-active & $1375(0.8)$ & 1 (ref) & \\
\hline Walk & $103(0.8)$ & $1.03(0.84$ to 1.26$)$ & 0.77 \\
\hline Cycle & $97(1.7)$ & 1.70 (1.37 to 2.10$)$ & $<0.001$ \\
\hline Mixed mode: walk & $142(0.7)$ & $0.93(0.78$ to 1.11$)$ & 0.43 \\
\hline Mixed mode: cycle & $171(1.3)$ & $1.53(1.30$ to 1.80$)$ & $<0.001$ \\
\hline \multicolumn{4}{|l|}{ Fractures: } \\
\hline Non-active & $4486(2.5)$ & 1 (ref) & \\
\hline Walk & $325(2.6)$ & $0.93(0.83$ to 1.05$)$ & 0.24 \\
\hline Cycle & $242(4.2)$ & $1.62(1.42$ to 1.86$)$ & $<0.001$ \\
\hline Mixed mode: walk & $521(2.5)$ & 0.98 (0.89 to 1.07) & 0.64 \\
\hline Mixed mode: cycle & $455(3.4)$ & $1.43(1.30$ to 1.58$)$ & $<0.001$ \\
\hline
\end{tabular}

Implications of findings and wider context

Cycling might carry an excess risk of injury from being in a vulnerable physical position compared to falls from when someone is on foot. A review of empirical data, however, concluded that clearly marked bike specific road facilities were consistently shown to provide improved safety for cyclists, reducing injury or crash rates by about half compared with unmodified roads. ${ }^{27}$ In other work it is debated whether physical segregation of cycle lanes offers more effective protection than painted cycle lanes. ${ }^{28-30}$ Our research cannot make specific recommendations in this respect, but suggests a need for both local and central

\begin{tabular}{|c|c|c|c|}
\hline Model and commute mode & $\begin{array}{l}\text { Mean* }(S D) \text { events } \\
\text { per } 100 \text { persons }\end{array}$ & $\begin{array}{l}\text { Adjusted rate ratiot } \\
(95 \% \mathrm{Cl})\end{array}$ & $P$ value \\
\hline \multicolumn{4}{|l|}{ Transport related incidents: } \\
\hline Non-active & $1.2(11.6)$ & 1 (ref) & \\
\hline Walk & $0.9(10.0)$ & 0.80 (0.66 to 0.97$)$ & 0.03 \\
\hline Cycle & $6.2(27.3)$ & $3.42(3.00$ to 3.90$)$ & $<0.001$ \\
\hline Mixed mode: walk & $0.9(9.9)$ & 0.79 (0.68 to 0.93$)$ & 0.003 \\
\hline Mixed mode: cycle & $4.2(21.9)$ & $2.62(2.37$ to 2.91$)$ & $<0.001$ \\
\hline \multicolumn{4}{|c|}{ Cycling related transport incidents (internal validation) } \\
\hline Non-active & $0.3(6.2)$ & 1 (ref) & \\
\hline Walk & $0.3(5.7)$ & $0.97(0.70$ to 1.37$)$ & 0.88 \\
\hline Cycle & $5.2(24.6)$ & $8.04(6.80$ to 9.51$)$ & $<0.001$ \\
\hline Mixed mode: walk & $0.3(5.7)$ & $0.92(0.69$ to 1.22$)$ & 0.56 \\
\hline Mixed mode: cycle & $3.0(18.4)$ & $5.52(4.77$ to 6.38$)$ & $<0.001$ \\
\hline
\end{tabular}

government to consider a wide range of options for improving cycling specific as well as general road safety, such as improved infrastructure including segregated cycling from main traffic flows, traffic calming, speed reductions, and improved training for all road users. ${ }^{28-35}$ In countries with a good cycling infrastructure, such as Denmark and the Netherlands, the risk of injuries from cycling are lower than in countries without such infrastructures. ${ }^{61619}$ Perceived dangers represent a deterrent to cycling for many ${ }^{17} 1836$ and thus to realise the potential public health benefits of increased participation in cycling, an important public health need exists to improve road safety for cyclists in the UK. The present findings suggest that if the UK aims to increase participation in cycling as a commute mode (and for other journeys), making the journey safer would further improve the risk: benefit balance.

In this UK setting, commuters were more likely to cycle to work if the distance between home and workplace was relatively short (12\% of commutes up to five miles involved cycling). For longer distances, motorised modes of transport were more common. Cyclists reported travelling more than 11 miles one way to work and would therefore be spending more time on the bicycle than shorter distance commuters, as shown by our analysis. A study by Mindell and colleagues ${ }^{19}$ showed a higher risk of hospital admission from cycling (admissions per million hours' use were 29 in men and 28 in women) versus those for driving (admissions per million hours' use 1.6 in men and 1.8 in women), but for cycling this included admissions linked with riskier competitive and leisure time cycling activities, so might overestimate the risks associated with commuting. Mindell and colleagues' study advocated that this time spent "at risk" during a journey should be considered a potential confounder or effect modifier in the analysis. ${ }^{19}$ Our data do consider time spent at risk on commute journeys as part of the analysis. However, the reality for an individual considering how to commute to work is that the time spent at risk is of limited relevance to daily life. The commute must be made by one mode or another. Our data suggest that there is currently an associated higher risk of injury when commuting by cycling, but also a lower risk of poor health outcomes.

\section{Strengths and limitations of this study}

The strengths of this study include the size of the cohort and its breadth of phenotyping, which allowed extensive individual level adjustment for the covariate in the models. We also adjusted our models for selfreported physical activity level, to attempt to account for non-commuting related activities that could have predisposed to higher risks of injury. Such approaches are often not possible using aggregate data or travel surveys. Weaknesses also require careful consideration. Because of the observational nature of the data caution is needed in inferring a causal association. As such, residual confounding is possible, but we show the association in several different models, and 
also a modification by commute distance. Obtaining reliable data on cycling associated injuries is difficult. Statistics on cycling uptake and the consequences of cycling are often gained from and modelled on data from government transport data and surveys. As such, populations and exposures between different studies are often not comparable. Outcome ascertainment in such studies often relies on aggregated population level data, or data that might be related to the severity of incidents such as the UK STATS19 police reports. ${ }^{37} 38$ Our study used two different approaches, but will misclassify injuries that did not lead to hospital admission or death (in all commuting groups). As information on commuting was gathered by self-report, recall and misclassification bias are possible, although non-differential misclassification would bias results to the null. UK Biobank is known to be non-representative of the general UK population, being skewed towards better health and affluence. UK Biobank assessment centres were located in large cities so included few people who lived rurally, limiting our ability to check for interaction between commute mode and urban versus rural areas. We also did not have data to investigate local cycling infrastructure on the commute to work for individuals, but a stratified model for those recruited during and after 2010 (which may correspond with greater cycling infrastructure in some areas), did not identify any interaction. We only use hospital length of stay as a proxy for injury severity. We cannot make generalisations between the associations we observe and all commuting locations in the UK.

\section{Conclusions and policy implications}

Our study provides evidence that in the UK commuter cycling, compared with non-active modes, is associated with a higher risk of injury but lower risk of cancer, cardiovascular disease, and mortality. The perception among the general public that cycling carries a greater risk of injury than other modes of commuter transport is supported by evidence, although the health benefits are considerable. To change public perception of cycling as a viable commute mode and gain the associated health benefits, local and national infrastructure planners need to improve the safety for cycling commuters.

We thank the UK Biobank participants. UK Biobank was established by the Wellcome Trust medical charity, Medical Research Council, Department of Health, Scottish government, and North west Regional Development Agency. It has also had funding from the Welsh Assembly government and the British Heart Foundation. This research has been conducted using the UK Biobank resource under application number 7155 .

Contributors: CW and CCM contributed equally to this work and are joint first authors. CW, CCM, FH, SG, JMRG, NS, JPP, and PW conceived and designed the study, advised on all statistical aspects, and interpreted the data. CW, CCM, FH, and PW did the statistical analysis. CW, CCM, and PW drafted the manuscript. All authors reviewed the manuscript and approved the final version to be published. All authors had full access to all the data in the study and take responsibility for the integrity of the data and the accuracy of the data analysis. CW, CCM, JPP, and PW are the guarantors. The corresponding author attests that all listed authors meet authorship criteria and that no others meeting the criteria have been omitted.

Funding: This study was supported by a grant from Chest, Heart, and Stroke Association Scotland (Res16/A165]) The research was designed, conducted, analysed, and interpreted by the authors entirely independently of the funding sources.

Competing interests: All authors have completed the ICMJE uniform disclosure form at www.icmje.org/coi_disclosure.pdf and declare: funding by a grant from Chest, Heart, and Stroke Association Scotland; IMRG, PW, CACM, NS, SRG, and JPP have received grant funding from British Cycling and HSBC UK for the Cycle Nation Project, a workplace based intervention to increase cycling participation, outside the submitted work; no other relationships or activities that could appear to have influenced the submitted work.

Ethical approval: UK Biobank received ethical approval from the North West Multi-centre Research Ethics Committee (REC reference: 11/NW/03820). All participants gave written informed consent before enrolment in the study, which was conducted in accordance with the principles of the Declaration of Helsinki.

Data sharing: Researchers can apply to use the UK Biobank resource and access the data used. No additional data available.

The manuscript's guarantors (CW, CCM, JPP, and PW) affirm that the manuscript is an honest, accurate, and transparent account of the study being reported; that no important aspects of the study have been omitted; and that any discrepancies from the study as planned (and, if relevant, registered) have been explained.

Dissemination to participants and related patient and public communities: There are no plans to disseminate the results of the research to study participants directly, but results will be made publicly available by open access publication, press release, and dissemination via social media and UK Biobank resources such as its website.

This is an Open Access article distributed in accordance with the Creative Commons Attribution Non Commercial (CC BY-NC 4.0) license, which permits others to distribute, remix, adapt, build upon this work non-commercially, and license their derivative works on different terms, provided the original work is properly cited and the use is noncommercial. See: http://creativecommons.org/licenses/by-nc/4.0/.

1 Celis-Morales CA, Gray S, Petermann F. et al, Walking Pace Is Associated with Lower Risk of All-Cause and Cause-Specific Mortality. Med Sci Sports Exerc 2019;51:472-80. doi:10.1249/ MSS.0000000000001795

2 Celis-Morales CA, Lyall DM, Steell L. et al, Associations of discretionary screen time with mortality, cardiovascular disease and cancer are attenuated by strength, fitness and physical activity: findings from the UK Biobank study. BMC Med 2018;16:77. doi:10.1186/s12916-018-1063-1

3 Ding D, Lawson KD, Kolbe-Alexander TL, et al, Lancet Physical Activity Series 2 Executive Committee. The economic burden of physical inactivity: a global analysis of major non-communicable diseases. Lancet 2016;388:1311-24. doi:10.1016/S0140-6736(16)30383-X

4 Lee IM, Shiroma EJ, Lobelo F, Puska P, Blair SN, Katzmarzyk PT, Lancet Physical Activity Series Working Group. Effect of physical inactivity on major non-communicable diseases worldwide: an analysis of burden of disease and life expectancy. Lancet 2012;380:219-29. doi:10.1016/S0140-6736(12)61031-9

5 Physical Inactivity and Sedentary Behaviour Report 2017. Foundation BH. 2017. https://www.bhf.org.uk/informationsupport/publications/ statistics/physical-inactivity-report-2017 (accessed 1st Nov 2019).

6 Pucher J, Buehler R, Bassett DR, Dannenberg AL. Walking and cycling to health: a comparative analysis of city, state, and international data. Am J Public Health 2010;100:1986-92. doi:10.2105/AJPH.2009.189324

7 Bassett DRJr, Pucher J, Buehler R, Thompson DL, Crouter SE. Walking, cycling, and obesity rates in Europe, North America, and Australia. J Phys Act Health 2008;5:795-814. doi:10.1123/jpah.5.6.795

8 Walking and cycling: local measures to promote walking and cycling as forms of travel or recreation. NICE. 2012. www.nice.org.uk/ guidance/ph41 (accessed 1st Nov 2019)

9 Audrey S, Procter S, Cooper AR. The contribution of walking to work to adult physical activity levels: a cross sectional study. Int J Behav Nutr Phys Act 2014:11:37. doi:10.1186/1479-5868-11-37

10 Blond MB, Rosenkilde M, Gram AS. et al, How does 6 months of active bike commuting or leisure-time exercise affect insulin sensitivity, cardiorespiratory fitness and intra-abdominal fat? A randomised controlled trial in individuals with overweight and obesity. Br J Sports Med 2019;53:1183-92. doi:10.1136/bjsports-2018-100036

11 Celis-Morales CA, Lyall DM, Welsh P et al, Association between active commuting and incident cardiovascular disease, cancer, and mortality: prospective cohort study. BMJ 2017;357:j1456. doi:10.1136/bmj.j1456

$12 \mathrm{Hu} \mathrm{G}$, Jousilahti P, Borodulin K. et al, Occupational, commuting and leisure-time physical activity in relation to coronary heart disease among middle-aged Finnish men and women. Atherosclerosis 2007;194:490-7. doi:10.1016/j.atherosclerosis.2006.08.051 
13 Hu G, Tuomilehto J, Borodulin K, Jousilahti P. The joint associations of occupational, commuting, and leisure-time physical activity, and the Framingham risk score on the 10-year risk of coronary heart disease. Eur Heart J 2007;28:492-8. doi:10.1093/eurheartj/ehl475

14 Hou L, Ji B-T, Blair A, Dai Q, Gao YT, Chow WH. Commuting physical activity and risk of colon cancer in Shanghai, China. Am J Epidemiol 2004;160:860-7. doi:10.1093/aje/kwh301

15 Hu G, Qiao Q, Silventoinen K. et al, Occupational, commuting, and leisure-time physical activity in relation to risk for Type 2 diabetes in middle-aged Finnish men and women. Diabetologia 2003;46:322-9. doi:10.1007/s00125-003-1031-x

16 Pucher J, Buehler R. Making Cycling Irresistible: Lessons from The Netherlands, Denmark and Germany. Transp Rev 2008;28:495-528. doi:10.1080/01441640701806612

17 British Social Attitudes Survey 2015: Public attitudes towards transport. Department for transport. 2017. https://assets. publishing.service.gov.uk/government/uploads/system/uploads/ attachment_data/file/586193/british-social-attitudes-survey-2015. pdf (accessed 1st Nov 2019).

18 Fraser SDS, Lock K. Cycling for transport and public health: a systematic review of the effect of the environment on cycling. Eur Public Health 2011;21:738-43. doi:10.1093/eurpub/ckq145

19 Mindell IS, Leslie D, Wardlaw M. Exposure-based, 'like-for-like' assessment of road safety by travel mode using routine health data. PLoS One 2012;7:e50606. doi:10.1371/journal.pone.0050606

20 Gill J, Baker G, Broadfoot S, et al. Confidence to ride. Confidence to invest - evidence review. 2019. https://www.britishcycling.org.uk/ zuvvi/media/bc_files/campaigning/2019/Glasgow_Report_digital single pages FINAL.pdf (accessed 1st Nov 2019).

21 Golbuff L, Aldred R, UEL Sustainable Mobilities Research Group. Cycling policy in the UK. A historical and thematic overview. 2011 http://rachelaldred.org/wp-content/uploads/2012/10/cyclingreview1.pdf (accessed 1st Nov 2019).

22 Transport Scotland. Cycling by design. 2010 https://www.transport. gov.scot/media/14173/cycling_by_design_2010_rev_1 june 2011.pdf (accessed 1st Nov 2019).

23 Department for Transport. Cycling and walking investment strategy. 2016 https://assets.publishing.service.gov.uk/government/uploads/ system/uploads/attachment data/file/512895/cycling-andwalking-investment-strategy.pdf (accessed 1st Nov 2019).

24 Hilbe JM. Modeling Count Data. 2014 Cambridge. Cambridge University Press, 2014.

25 The global action plan on physical activity 2018-2030. WHO. 2018 https://www.who.int/ncds/prevention/physical-activity/gappa/ action-plan (accessed 1st Nov 2019).

26 Rojas-Rueda D, de Nazelle A, Tainio M, Nieuwenhuijsen MJ. The health risks and benefits of cycling in urban environments compared with car use: health impact assessment study. BMJ 2011;343:d4521. doi:10.1136/bmj.d4521

27 Reynolds CCO, Harris MA, Teschke K, Cripton PA, Winters M. The impact of transportation infrastructure on bicycling injuries and crashes: a review of the literature. Environ Health 2009;8:47. doi:10.1186/1476-069X-8-47

28 Lusk AC, Furth PG, Morency P, Miranda-Moreno LF, Willett WC, Dennerlein JT. Risk of injury for bicycling on cycle tracks versus in the street. Inj Prev 2011;17:131-5. doi:10.1136/ip.2010.028696

29 Lusk AC, Morency P, Miranda-Moreno LF, Willett WC, Dennerlein JT. Bicycle guidelines and crash rates on cycle tracks in the United States. Am J Public Health 2013;103:1240-8. doi:10.2105/ AlPH.2012.301043

30 Thomas B, DeRobertis M. The safety of urban cycle tracks: a review of the literature. Accid Anal Prev 2013;52:219-27. doi:10.1016/j. aap.2012.12.017

31 Teschke K, Harris MA, Reynolds CCO. et al, Route infrastructure and the risk of injuries to bicyclists: a case-crossover study. Am J Public Health 2012;102:2336-43.

32 Marshall W, Ferenchak N. Why cities with high bicycling rates are safer for all road users. J Transp Health 2019;13:100539. doi:10.1016/j.jth.2019.03.004

33 Morrison CN, Thompson J, Kondo MC, Beck B. On-road bicycle lane types, roadway characteristics, and risks for bicycle crashes. Accid Anal Prev 2019;123:123-31. doi:10.1016/j.aap.2018.11.017

34 Zangenehpour S, Strauss J, Miranda-Moreno LF, Saunier N. Are signalized intersections with cycle tracks safer? A case-control study based on automated surrogate safety analysis using video data. Accid Anal Prev 2016;86:161-72. doi:10.1016/j.aap.2015.10.025

35 Grundy C, Steinbach R, Edwards P, Green J, Armstrong B, Wilkinson P. Effect of $20 \mathrm{mph}$ traffic speed zones on road injuries in London, 1986-2006: controlled interrupted time series analysis. BM/ 2009.339.b4469 doi:10.1136/bmi.b4469

36 Iwińska K, Blicharska M, Pierotti L, Tainio M, de Nazelle A. Cycling in Warsaw, Poland - Perceived enablers and barriers according to cyclists and non-cyclists. Transp Res Part A Policy Pract 2018;113:291-301. doi:10.1016/j.tra.2018.04.014

37 Aldred R, Goodman A, Gulliver J, Woodcock J. Cycling injury risk in London: A case-control study exploring the impact of cycle volumes, motor vehicle volumes, and road characteristics including speed limits. Accid Anal Prev 2018;117:75-84. doi:10.1016/j. aap.2018.03.003

38 Woodcock J, Tainio M, Cheshire J, O'Brien O, Goodman A. Health effects of the London bicycle sharing system: health impact modelling study. BMJ 2014;348:g425. doi:10.1136/bmj.g425

Supplementary material: additional tables 1-6 